\title{
PROMOVIENDO EL DEBATE SOBRE EL MODELO ORGANIZATIVO DE UNIVERSIDAD
}

\section{PROMOTING A DEBATE ON THE UNIVERSITY ORGANIZATION MODEL}

\author{
Carlos Martín-Ríos cmartinrios@cminnovation.org \\ Center for Organizational Learning \& Transformation. Rutgers University. EEUU. \\ Center for Management Innovation. Madrid. España.
}

\author{
ChaRLes HeCKscher checkscher@work.rutgers.edu \\ Center for Organizational Learning \& Transformation. Rutgers University. EEUU.
}

Ciertamente, el actual modelo universitario está en crisis. Tal y como ponen de manifiesto los artículos elaborados por los especialistas españoles, latinoamericanos y norteamericanos incluidos en este debate y que oportunamente publica la Revista Internacional de Sociología, la universidad pública en general y la española en concreto, afronta un grave problema organizativo y de gestión. Como consecuencia de la universalización de la educación y del nuevo papel que se le otorga a las universidades en la sociedad del conocimiento, en las últimas décadas éstas han experimentado un crecimiento sin precedentes en la demanda de títulos que otorgan. Se han establecido mayores controles formales de calidad del servicio y rankings más o menos informales con los que dar un servicio al consumidor, consolidar la información y ayudar a tomar decisiones más adecuadas. Las universidades por su parte han visto como la mayor demanda de sus servicios, además de ofrecer unas oportunidades de crecimiento inimaginables en su historia, ha venido acompañada de mayores exigencias. Todo lo cual les enfrenta a unos retos externos e internos que hacen temblar los cimientos sobre los que se asientan. La longevidad de la institución incita a creer en su capacidad de reacción; pero la magnitud de los cambios hace temer que dicha reacción pueda no ser suficiente.

Uno de los grandes retos es adecuar el modelo organizativo a las exigencias actuales: mayor compromiso hacia las necesidades de los múltiples stakeholders (los propios empleados, los alumnos y sus familias, las comunidades locales a las que sirven, las instituciones, el tejido productivo y la sociedad en general), mayor agilidad y adaptación a los cambios económicos, sociales, políticos y culturales, y mayor capacidad de provisión y autonomía financiera. La tesis de nuestro trabajo es que debemos enfrentar los retos con un nuevo modelo de organización del trabajo: la universidad colaborativa, como contrapunto a las derivas burocráticas que muchos consideran inevitables. $Y$ en ese punto situar el debate sobre la posible reacción de la universidad en sus tres frentes: investigación, docencia y transferencia. 
La universidad pública es escéptica, cuando no abiertamente hostil, a la modernización de la gestión y cultura organizativa, muchos de sus cuadros encallados en un discurso yermo que contrapone la labor social y la modernizadora de la universidad. Ofrecer alternativas a la deriva hacia la que camina la universidad es una tarea urgente. Hay que repensar los objetivos fundamentales de las universidades y los matices entre modelos alternativos, plantean en sus artículos Salaburu y los profesores Lozada y Guiterrez. Análisis como el del Fernández Enguita nos recuerdan como otras instituciones y empresas privadas han realizado ese giro. El modelo de gestión burocrático cada más imperante parece, a priori, una respuesta natural a los males que el nuevo escenario deja al descubierto y con la que solventar la falta de información, la tradicional ausencia de mecanismos de rendición de cuentas de los académicos y, como resultado, la enorme incertidumbre en la gestión universitaria. Como afirma la profesora Pasamar, a ello contribuyen la existencia de sistemas de control de calidad tan poco eficientes como los sistemas de acreditación de profesorado (¿es sostenible exigir mayor colaboración e interdisciplinariedad académica mientras se penaliza el número de investigadores firmantes de un estudio?) o las convocatorias de investigación (¿es sensato que la burocratización de las convocatorias haga imprescindible la existencia de una industria experta en asesorar a los científicos en la redacción de propuestas?). En paralelo, los modelos docentes rígidos ofrecen sensación de claridad y estabilidad a expensas de una clara falta de adecuación a las demandas sociales, apuntan Erhardt y Manev.

Por tanto, se hace necesario llevar a cabo investigaciones empíricas en los diversos aspectos organizativos y de gestión universitaria. Los expertos de la Ciencia de la Administración necesitan involucrase en esta tarea y participar en investigaciones colaborativas con otras disciplinas como la Sociología de la Educación - la Economía con mayor experiencia en estas materias. Se trata de llevar a cabo análisis estadísticos longitudinales, investigaciones experimentales, etnografías y estudios de caso comparativos con los que desarrollar inventarios de experiencias organizativas en universidades de todo el planeta, profundizar sobre aquellos centros en los que la misión de transferencia constituye el núcleo central de la institución, examinar el impacto de iniciativas como el crowdfunding y la investigación abierta y colaborativa, o verificar las posibilidades docentes de las plataformas de recursos y cursos abiertos y masivos. Por supuesto, estas son sólo algunas de las cuestiones que requieren ser abordadas.

Debemos comenzar a debatir cuál debe ser el verdadero papel de la universidad en nuestro tiempo. Es ahí donde la investigación sobre la universidad colaborativa debe jugar un papel esencial en la transformación de la realidad académica.

RECIBIDO: 05/02/2013

ACEPTADO: 09/07/2013 